\title{
Prevalence and pathogenicity of autoantibodies in patients with idiopathic CD4 lymphopenia
}

\author{
Ainhoa Perez-Diez, ${ }^{1}$ Chun-Shu Wong, ${ }^{1}$ Xiangdong Liu, ${ }^{1}$ Harry Mystakelis, ${ }^{1}$ Jian Song, ${ }^{2}$ Yong Lu, ${ }^{2}$ Virginia Sheikh, \\ Jeffrey S. Bourgeois, ${ }^{1}$ Andrea Lisco, ${ }^{1}$ Elizabeth Laidlaw, ${ }^{1}$ Cornelia Cudrici, ${ }^{3}$ Chengsong Zhu, ${ }^{4}$ Quan-Zhen Li, ${ }^{4,5}$ \\ Alexandra F. Freeman, ${ }^{6}$ Peter R. Williamson, ${ }^{7}$ Megan Anderson, ${ }^{1}$ Gregg Roby, ${ }^{1}$ John S. Tsang, ${ }^{2,8}$ Richard Siegel, ${ }^{3}$ and Irini Sereti ${ }^{1}$ \\ ${ }^{1}$ HIV Pathogenesis Section, Laboratory of Immunoregulation, and 2Multiscale Systems Biology Section, Laboratory of Immune System Biology, National Institute of Allergy and Infectious Diseases (NIAID), \\ and ${ }^{3}$ mmmunoregulation Section, Autoimmunity Branch, National Institute of Arthritis and Musculoskeletal and Skin Diseases, NIH, Bethesda, Maryland, USA. ${ }^{4}$ Microarray Core Facility and ${ }^{5}$ Department of

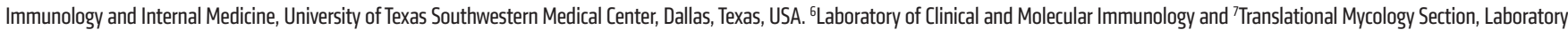 \\ of Clinical and Molecular Immunology, NIAID, and ${ }^{8}$ Trans-NIH Center for Human Immunology, NIH, Bethesda, Maryland, USA.
}

\begin{abstract}
BACKGROUND. Idiopathic CD4 lymphopenia (ICL) is defined by persistently low CD4+ cell counts ( $<300$ cells $/ \mu \mathrm{L})$ in the absence of a causal infection or immune deficiency and can manifest with opportunistic infections. Approximately $30 \%$ of ICL patients develop autoimmune disease. The prevalence and breadth of their autoantibodies, however, and their potential contribution to pathogenesis of ICL remain unclear.
\end{abstract}

\begin{abstract}
METHODS. We hybridized 34 and 51 ICL patients' sera to a 9,000-human-proteome array and to a 128-known-autoantigen array, respectively. Using a flow-based method, we characterized the presence of anti-lymphocyte Abs in the whole cohort of 72 patients, as well as the Ab functional capability of inducing Ab-dependent cell-mediated cytotoxicity (ADCC), complement deposition, and complement-dependent cytotoxicity (CDC). We tested ex vivo the activation of the classical complement pathway on ICL CD4+ $T$ cells.
\end{abstract}

\begin{abstract}
RESULTS. All ICL patients had a multitude of autoantibodies mostly directed against private (not shared) targets and unrelated quantitatively or qualitatively to the patients' autoimmune disease status. The targets included lymphocyte

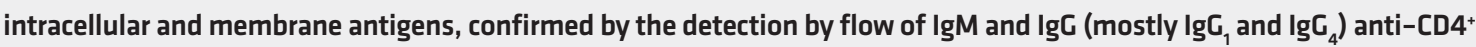
cell Abs in $50 \%$ of the patients, with half of these cases triggering lysis of $\mathrm{CD} 4^{+} \mathrm{T}$ cells. We also detected in vivo classical complement activation on $\mathrm{CD}^{+} \mathrm{T}$ cells in $14 \%$ of the whole cohort.
\end{abstract}

CONCLUSION. Our data demonstrate that a high prevalence of autoantibodies in ICL, some of which are specific for CD4+ $T$ cells, may contribute to pathogenesis, and may represent a potentially novel therapeutic target.

TRIAL REGISTRATION. ClinicalTrials.gov NCT00867269.

FUNDING. NIAID and National Institute of Arthritis and Musculoskeletal and Skin Diseases of the NIH.

\section{Introduction}

Idiopathic CD4 lymphopenia (ICL) was initially described in the late 1980s when some patients presented with opportunistic infections and CD4 lymphopenia consistent with AIDS, but with negative HIV testing. A Centers for Disease Control investigation ensued that led to the definition of ICL as persistently low $\mathrm{CD} 4^{+}$cell counts $(<300$ cells $/ \mu \mathrm{L})$ in the absence of an infection, condition, or therapy known to cause lymphopenia (1). The Centers for Disease

\section{Related Commentary: p. 5105}

Authorship note: APD and CSW share first authorship.

Conflict of interest: The authors have declared that no conflict of interest exists. Copyright: () 2020, American Society for Clinical Investigation.

Submitted: January 7, 2020; Accepted: June 24, 2020; Published: August 31, 2020

Reference information: J Clin Invest. 2020;130(10):5326-5337.

https://doi.org/10.1172/JCI136254.
Control investigation concluded that there was no familial linkage or evidence of a transmissible agent. Almost 40 years later, the etiology of ICL remains unclear, and there is no specific therapeutic approach other than use of prophylactic antibiotics, treatment of infections, and screening for infection-related malignancies.

Three large cohorts have been studied to date describing the main clinical manifestations of ICL, which include opportunistic infections, cryptococcal disease, and other invasive fungal or nontuberculous mycobacteria infections, human papilloma virusassociated (HPV-associated) diseases, and/or malignancies and autoimmunity (2-4). Regarding autoimmune diseases in ICL, it can be difficult to ascertain cause and effect but there are instances where it is clear that ICL diagnosis predated clinical autoimmune manifestations (2).

The etiology/ies of ICL have been investigated throughout the past several decades and may involve insufficient production of $\mathrm{T}$ lymphocytes, impaired proliferation, and increased periph- 


\section{Table 1. Clinical and immunological characteristics of the ICL participants}

\begin{tabular}{|c|c|c|}
\hline Characteristic $(n=72)$ & Value $^{A}$ & Normal range ${ }^{B}$ \\
\hline Age & 51 (range: 20-77) & - \\
\hline Sex & 38 Male, 34 Female & - \\
\hline Median follow up (years) & $3(2-4)$ & - \\
\hline Infectious complications ${ }^{\complement}$ & $51(71 \%)$ & - \\
\hline Autoimmunity & $22(31 \%)$ & - \\
\hline $\mathrm{CD}^{+}$cells $/ \mu \mathrm{L}$ & $315(134-568)$ & $714-2266$ \\
\hline $\mathrm{CD4}^{+}$cells $/ \mu \mathrm{L}$ & $75(32-156)$ & $359-1565$ \\
\hline $\mathrm{CD}^{+}$cells $/ \mu \mathrm{L}$ & $154(54-293)$ & $178-853$ \\
\hline NK cells/ $\mu \mathrm{L}$ & $130(91-177)$ & $126-729$ \\
\hline B cells $/ \mu \mathrm{L}$ & $126(54-293)$ & $61-320$ \\
\hline Serum lgG, mg/dL & 842 (696-1087) & $700-1600$ \\
\hline Serum IgM, mg/dL & $79(56-127)$ & $40-230$ \\
\hline \multicolumn{3}{|c|}{$\begin{array}{l}\text { ALymphocyte counts and serum concentrations shown as median with } \\
\text { interquartile ranges in parenthesis measured on the day of the anti-CD4 } \\
\text { Ab testing. }{ }^{B} \text { Normal range ( } 95 \% \text { reference interval) reported from clinical } \\
\text { laboratory at the NIH Clinical Center. Infectious agents and number } \\
\text { of patients: HPV, 26; Cryptococcus, } 19 \text {; varicella zoster virus (VZV), 11; } \\
\text { molluscum contagiosum, 8; histoplasma, 3; progressive multifocal } \\
\text { leukoencephalopathy (PML), 2; Mycobacterium avium complex (MAC), } \\
\text { 2; HSV-1, 2; CMV, 2; Candida, 1; Pneumocystis carinii pneumonia (PCP), 1; } \\
\text { Kaposi's sarcoma herpesvirus (KSHV), } 1 \text {. }\end{array}$} \\
\hline
\end{tabular}

eral destruction and/or sequestration, as suggested by decreased expression of CXCR4 in one study (5). Genetic evaluation has revealed a specific genetic defect in only a few cases $(3,5-7)$. Overall, the differences in infection susceptibility and variant concomitant cytopenias in certain patients (low $\mathrm{CD} 8^{+}$lymphocytes or B cells or NK cells) strongly suggest heterogeneous etiologies, as supported in our recent humanized mouse model study (8). It is conceivable that some common features among patients with ICL, for example increased cycling of $\mathrm{CD} 4^{+} \mathrm{T}$ cells or decreased naive $\mathrm{T}$ cells, may reflect compensatory mechanisms of lymphopenia, ongoing infections, or consequences of ineffective lymphopenia-induced proliferation and not necessarily the inciting etiology of lymphopenia.

Chronic lymphopenia, regardless of etiology, has been associated with increased incidence of autoimmunity, although the molecular mechanisms involved are still unknown (9-11). Lymphopenia is a predictor of systemic lupus erythematosus (SLE) flares $(12,13)$, development of autoantibodies in primary Sjögren's syndrome (14), and dermatomyositis (5). Previously, studies have shown that autoantibodies are present in other conditions with CD4 lymphopenia $(15,16)$, suggesting an association between lymphopenia and anti-lymphocyte Abs. Moreover, it has been shown that primary immunodeficiencies (PIDs) are associated with a higher risk of autoimmune complications than the general population (17), with the greatest risk linked to T cell PIDs and common variable immunodeficiency. Importantly, PID patients with autoimmune/inflammatory complications before allogenic stem cell transplantation had reduced survival even after stem cell transplantation (17). In the context of ICL, however, it is still unclear whether the autoimmune disease observed in approximately $30 \%$ of the patients is one of the underlying causes of auto- antibody production, or if the lymphopenia itself plays a role in potentiating autoantibody production.

We hypothesized that given the high incidence of autoimmune diseases in ICL and our previous findings suggesting evidence of intact $T$ cell development, ineffective peripheral proliferation of lymphocytes, and lack of sequestration $(8,18)$, peripheral destruction of lymphocytes potentially mediated by autoantibodies may be playing a role in ICL pathogenesis. We thus evaluated the prevalence and potential pathogenicity of autoantibodies in ICL. We report that autoantibodies are highly prevalent in ICL and may actively impede lymphocyte recovery by Ab-dependent cell-mediated cytotoxicity (ADCC) and complement-dependent cytotoxicity (CDC).

\section{Results}

Patient cohort. We evaluated a cohort of ICL patients referred to the NIH for enrollment in our ICL protocol (NCT 00867269). The participants' characteristics are shown in Table 1. Briefly, the median age was 51 years (range 20 to 77 years) and there was an even distribution of sex, with 34 women and 38 men. The median $\mathrm{CD}^{+}$ count was 75 cells $/ \mu \mathrm{L}$ and the median $\mathrm{CD} 8^{+}$count was 154 cells/ $\mu \mathrm{L}$. Seventy-one percent had an infectious complication and $31 \%$ had an autoimmune diagnosis. Additional detailed patient clinical and laboratory characteristics are shown in Supplemental Table 1 (supplemental material available online with this article; https:// doi.org/10.1172/JCI136254DS1). Although at the outset of this project a total of 77 patients were included, 5 patients were excluded in final analyses due to diagnoses that could explain their $\mathrm{CD} 4^{+}$ $\mathrm{T}$ cell lymphopenia, specifically Crohn's disease (patient experienced $\mathrm{CD}^{+}$recovery to $>400$ cells $/ \mu \mathrm{L}$ after treatment with antiTNF- $\alpha$ antibody), and mutations in FAS (16), PI3KCD, NF- $\kappa B 1$, or DOCK- 8 unveiled after sequencing.

Measurement of IgG and IgM autoantibodies in ICL patients by autoantigen array. Although lymphopenia has been linked to the development of autoimmunity (11), it is still unknown whether the persistent lymphopenia in ICL patients is associated with elevated levels of autoantibodies. To assess the prevalence of autoantibodies in ICL, we evaluated sera from 51 ICL patients and 25 healthy controls (HCs) using a 124-plex autoantigen microarray for IgG and IgM Abs against clinically relevant autoantigens (19). In order to compare the ICL and HC groups, we calculated the ratio (ICL/ $\mathrm{HC}$ ) of each group mean Ab score for each target (see Methods) and displayed them as 2 volcano plots, for antigens recognized by IgG or IgM (Figure $1 \mathrm{~A})$. A ratio of mean $\mathrm{Ab}$ scores greater than 2 and with a corrected $P$ value less than 0.0004 (Bonferroni's correction) identified autoantigens significantly recognized by Abs in the ICL sera. This ICL versus HC comparison showed that the ICL group had significant levels of IgG and IgM Abs against 57 and 39 autoantigens, respectively, while the HC group had none. The top 3 IgG autoantibodies found in ICL sera (Supplemental Table 2) have been previously associated with different autoimmune syndromes, such as anti-threonyl-tRNA synthetase (anti-PL-7), associated with anti-synthetase syndrome (7); anti-myeloperoxidase (anti-MPO), associated with vasculitis (20) and granulomatosis with polyangiitis (21); and anti-muscarinic receptor, associated with Sjögren's syndrome (22). The top IgM autoantibodies (Supplemental Table 3) targeted collagen VI, small nuclear ribonucleo- 
A
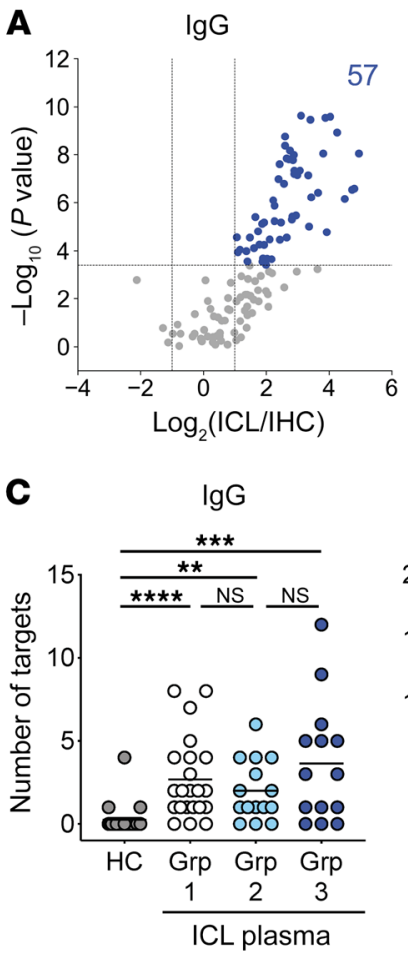

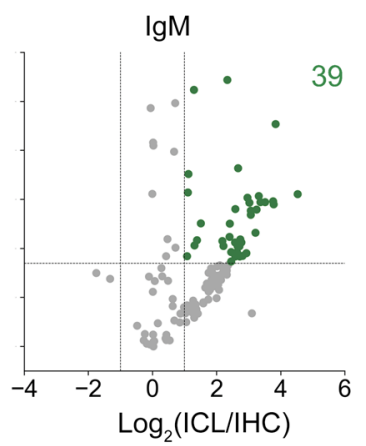

B

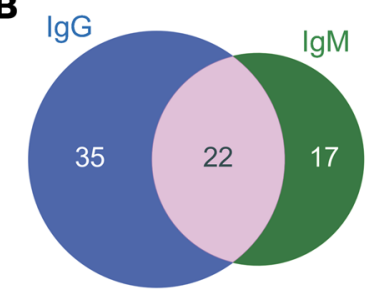

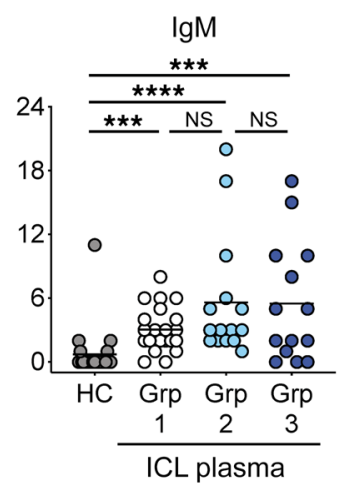

Figure 1. ICL patients have increased prevalence of IgG and IgM autoantibodies compared with healthy controls. Sera from 51 ICL patients and 25 HCs were screened for autoantibodies using a high-throughput 124 autoantigen microarray platform. (A) Volcano plots of the IgG and IgM autoantibodies, on the left and the right, respectively, displaying $-\log _{10}\left(P\right.$ value) on the $y$ axis versus $\log _{2}$ (average $A b$ score in ICL samples/average Ab score in HC samples) on the $x$ axis. Each circle represents an autoantibody, highlighting in blue (IgC) or green (IgM) the statistically significant positive autoantibodies between the HC and ICL groups, calculated with the nonparametric Mann-Whitney test with Bonferroni's correction. Only targets having $P<0.05 / 122$ (with 122 being the number of comparisons) were considered significant and are highlighted. (B) Venn diagram showing antigens recognized by both IgG and IgM (pink) vs. by only IgG (blue) or only IgM (green) autoantibodies. (C) Number of autoantibody targets with $Z \geq 4$ for HCs and each subgroup of ICL patients. $Z$ scores for each target were calculated as the number of standard deviations the Ab score was above the mean of the HC Ab score for of each target. Group 1 (open circles, $n=22$ ) corresponds to ICL patients without a diagnosed autoimmune disease and without a positive test for a set of clinical autoantibodies. Group 2 (cyan circles, $n=15$ ) corresponds to patients who tested positive for clinical autoantibodies but did not meet clinical criteria for any specific autoimmune diagnosis. Group 3 (blue circles, $n=14$ ) corresponds to patients who had been diagnosed with 1 or more autoimmune disease. Data were pooled from 2 independent experiments. ${ }^{* *} P<0.01$; ${ }^{* * *} P<$ $0.001 ;{ }^{* * *} P<0.0001$ by Kruskal-Wallis test and Dunn's correction for multiple comparisons.

fied the number of targets that each sample recognized at $Z \geq 4$. The $Z$ score indicates how many standard deviations (SDs) an individual data point is from the population mean. Figure 1C shows that although each group of ICL patients had more autoantigens targeted by $\operatorname{IgG}$ and $\operatorname{IgM}$ autoantibodies than HCs, there was no significant difference in the number of antigens recognized by IgG or IgM Abs among the 3 ICL subgroups. Further, supervised hierarchical clustering heatmap analysis based on the 57 and 39 autoantigens recognized by ICL IgG and IgM showed a similar pattern among all the ICL samples, with no obvious subgrouping (Supplemental Figure 1, B and C). Principal component analysis (PCA) also showed segregation of individual ICL patients from $\mathrm{HCs}$ (Adonis paired test $P<0.05$ ), albeit with a few of the ICL patients from the 3 autoimmune groups clustering closer to the HC than to ICL samples (Supplemental Figure 1D). The IgG and IgM autoreactivities found in the ICL group were not driven by individual patients belonging to a specific autoimmunity group (Supplemental Figure 1, E and F). Overall, these results show that ICL patients have IgG and IgM autoantibodies against more autoantigens than HC individuals, and that the number and specificity of the autoantibodies show heterogeneity not explained by the patient's clinical autoimmune status.

Measurement of IgG autoantibod-

protein D1 (SmD1), and fibrinogen S, which have been associated with vasculitis and SLE (23), SLE (24), and rheumatoid arthritis (24), respectively. Out of all the autoantigens recognized by the ICL patients' sera, 22 (30\%) were recognized by both IgG and IgM Abs (Figure 1B and Supplemental Table 2, pink), including 4 of the top 6 targets mentioned above.

ICL patients were divided into 3 groups according to their clinical diagnosis of autoimmune disease and presence of clinical autoantibodies: group 1 were patients without a diagnosed autoimmune disease and without any serological evidence of clinical autoantibodies; group 2 were patients seropositive for clinical autoantibodies but not meeting clinical criteria for any specific autoimmune diagnosis; and group 3 patients were diagnosed with one or more autoimmune diseases. Supplemental Figure $1 \mathrm{~A}$ shows the distribution of these 3 ICL groups within the total 51 patients tested. In order to test next whether the 3 groups of patients displayed different levels of autoreactivities, we quanti- ies against the human proteome in ICL patients. To investigate autoreactivity of Abs from ICL patients against a broader spectrum of protein targets, we screened sera from 34 ICL patients, evenly distributed among the 3 previously described subgroups 1, 2, and 3 (with 12, 11, and 11 patients per group, respectively), and from 15 age-matched HCs for the presence of IgG Abs using the Thermo Fisher Scientific Human Protein Microarray. This array contains over 9,000 purified full-length human proteins in their native conformations, allowing for the detection of autoantibodies against the entire human proteome. Because of the large heterogeneity observed in the $\mathrm{Ab}$ response in this ICL cohort, we proceeded to an individual analysis by calculating and comparing the $Z$ score for each protein in each sample, as previously done on studies with high interpatient heterogeneity (25).

At $Z \geq 1$ and $Z \geq 2$ the ICL and HC groups were indistinguishable (Supplemental Figure 2A). At $Z \geq 3$, ICL patients displayed higher autoreactivity than HCs, with sera from all 34 ICL patients 
A

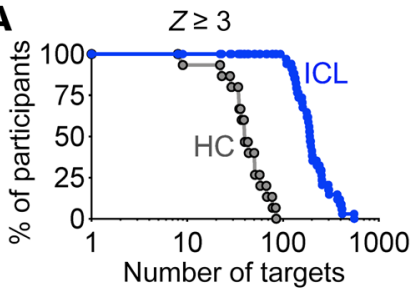

B

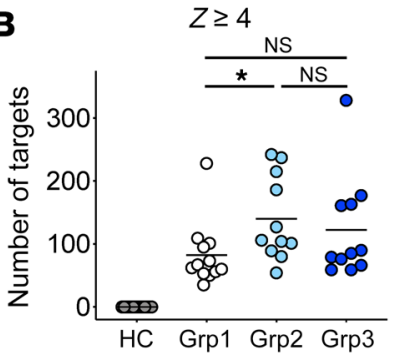

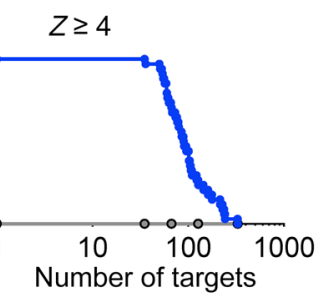

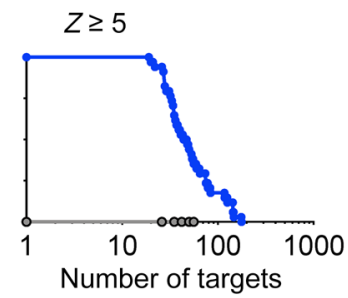

C

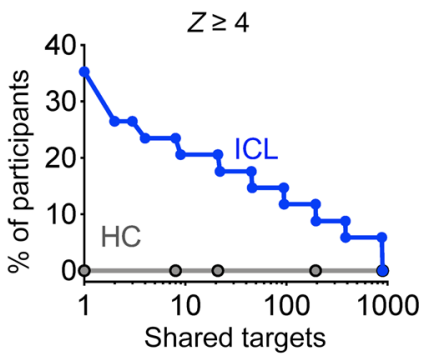

Figure 2. ICL patients have high levels of IgG autoantibodies against a wide range of human proteins. Sera from ICL patients $(n=34)$ and HCs $(n=15)$ were screened for the presence of autoantibodies using the Human Protein Microarray v5.2. Sera were incubated on a microarray that displays over 9,000 full-length purified human proteins in their native conformations. Data were batch corrected, filtered for relative fluorescence units (RFUs) $>500$ for at least 1 sample for each particular protein, and normalized. The $Z$ score for each target was calculated as the number of standard deviations the signal for a specific target had above the mean of the HCs. (A) Proportion of HC (gray) or ICL patients (blue) that had IgC Abs at $Z$ scores $\geq 3, \geq 4$, or $\geq 5$. (B) Number of proteins targeted by lgC Abs with $Z$ score $\geq 4$ from individual HC (gray) or patients' sera grouped according to autoimmune status, as described in Figure 1C. (C) Percentage of participants (HC, gray; ICL, blue) that shared any of the 2,159 targets found at $Z \geq 4$. Data were pooled from 3 independent experiments. ${ }^{*} P<0.01$ by KruskalWallis test and Dunn's correction for multiple comparisons.

recognizing at least 100 proteins (and around half of the patients recognizing 200), which was not observed in any of the 15 HCs' sera (Figure $2 \mathrm{~A}$ ). At $Z \geq 4$, none of the HC samples displayed autoreactivity, and half of the ICL patients demonstrated autoreactivity against 90 proteins (Figure 2A). Moreover, we accounted for 2,159 reactivities at $Z \geq 4$ when combining all the positive autoantibodies from all ICL samples. Most of these reactivities were very strong and persisted after increasing the threshold to $Z \geq 5$ (Figure 2A). Therefore, at the stringent threshold of $Z \geq 4$, all 34 ICL patients had Abs against a range of 35 to 328 human proteins and the $\mathrm{HC}$ individuals had none.

We asked whether there was a quantitative difference among the 3 ICL clinical autoimmunity groups. At $Z \geq 4$, group 1 ICL patients had slightly fewer targets compared with group 2 but not group 3 (Figure 2B). Despite the clinical diagnosis of autoimmune disease in group 3, the number of targeted proteins in this group was not higher than in the rest of the patients. We next analyzed the complexity of the autoantibody response found in ICL patients at $Z \geq 4$ by identifying how many of the 2,159 reactivities were shared among the ICL patients. Figure $2 \mathrm{C}$ shows that most of the targets were private (not shared), with the 21 most highly shared ones found in just $21 \%$ of the ICL patients and recognizing both intra- and extracellular proteins like UGT3A1 and PDGFß, respectively, as well as plasma membrane proteins like DKK4 (Supplemental Table 4). A similar dearth of shared targets was also seen at $Z \geq 3$ (Supplemental Figure 2B), where we also observed that none of the total 668 targets recognized by the $15 \mathrm{HC}$ samples were shared by even just 2 samples.

To look for possible qualitative differences discriminating between the patients developing autoimmune disease versus those who do not, we analyzed the list of 3,418 targets found at $Z \geq 3$ to identify the most common targets found in group 3 that were not present, or were present in just a few patients, in the other 2 groups. We found only 4 targets (LETM1, AASDHPPT, SPRED1, and PRSS33) present in at least $36 \%$ of group 3 patients and in a significantly lower percentage of the non-autoimmune disease groups 1 and 2 (Supplemental Table 5). Therefore, despite testing against the whole human proteome, we could not find major quantitative or qualitative differences in target recognition between the ICL patients with and without autoimmune disease, although the 4 antigens mentioned above might be potentially interesting targets for future investigation.

Notwithstanding the lack of shared targets in the ICL group, we asked whether there might be common biochemical pathways and/or specific cells targeted by these broad-spectrum Abs. To test this, we analyzed the list of 2,159 targets found at $Z \geq 4$ with Ingenuity Pathway Analysis and found that 2 of the their 4 most significant top upstream regulators were CD3 and TCR (Supplemental Figure 2C), suggesting that perhaps $\mathrm{CD}^{+} \mathrm{T}$ cells were targeted by the ICL autoantibodies. Examples of the 99 targeted proteins found to be expressed by $\mathrm{CD}^{+} \mathrm{T}$ cells were membrane molecules (CD45, IL-7R, CD4OL, and CD2), transcription factors (JunB and Gata-3), and secreted proteins (TNF and IL-2). These results confirm that ICL patients have IgG autoantibodies against a multitude of self-antigens and that, even though the majority of these Abs are private, some of them target proteins expressed on $\mathrm{CD}^{+} \mathrm{T}$ cells.

Detection of IgG and IgM Abs against $C D 3^{+} T$ cells in ICL patients. To determine whether the autoantibodies found in ICL sera were specific for T lymphocytes, we developed an in vitro assay to detect autoantibody binding to $\mathrm{HC}$ peripheral blood mononuclear cells (PBMCs). Briefly, HC PBMCs were incubated with sera from $\mathrm{HC}$ or ICL patients. Cells were washed and stained for human IgG (or its isotypes) and human IgM. Figure $3 \mathrm{~A}$ shows representative IgG and IgM staining on $\mathrm{HC} \mathrm{CD4} 4^{+} \mathrm{T}$ cells. We tested sera from all $72 \mathrm{ICL}$ patients and observed anti-CD $4^{+} \mathrm{T}$ cell IgG in 22 patients (30\%), and anti-CD4 $4^{+} \mathrm{T}$ cell IgM in 21 patients (29\%) (Figure 3B). There was no correlation between IgG and IgM Abs found in individual patients (Figure $3 \mathrm{C}$ ). We also detected $\operatorname{Ig} G$ and IgM Abs binding to $\mathrm{CD} 8^{+} \mathrm{T}$ cells, NK cells, and B cells (Figure 3D), and found less frequent Abs against NK cells and IgM Ab against B cells. There was a strong correlation $(r=0.938, P<0.0001)$ between the presence of anti-CD $4^{+} \mathrm{T}$ cell IgG and anti-CD8 ${ }^{+} \mathrm{T}$ cell IgG in the same 
A

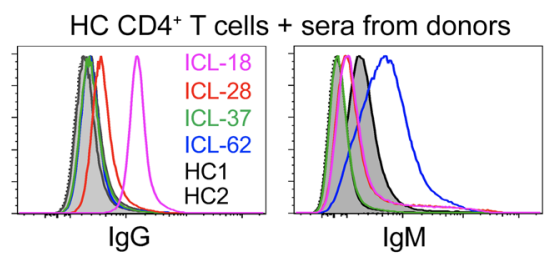

B

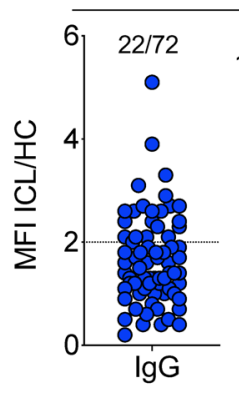

C

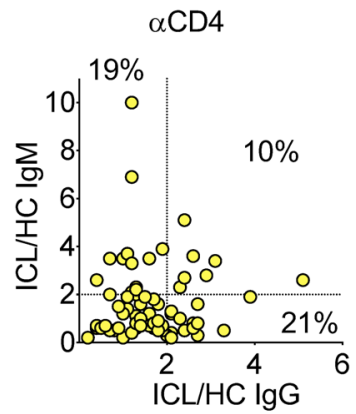

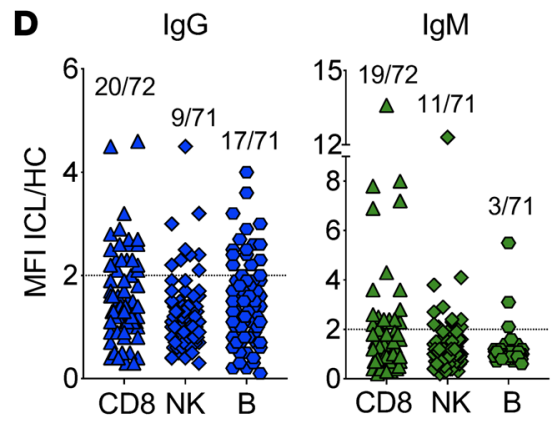
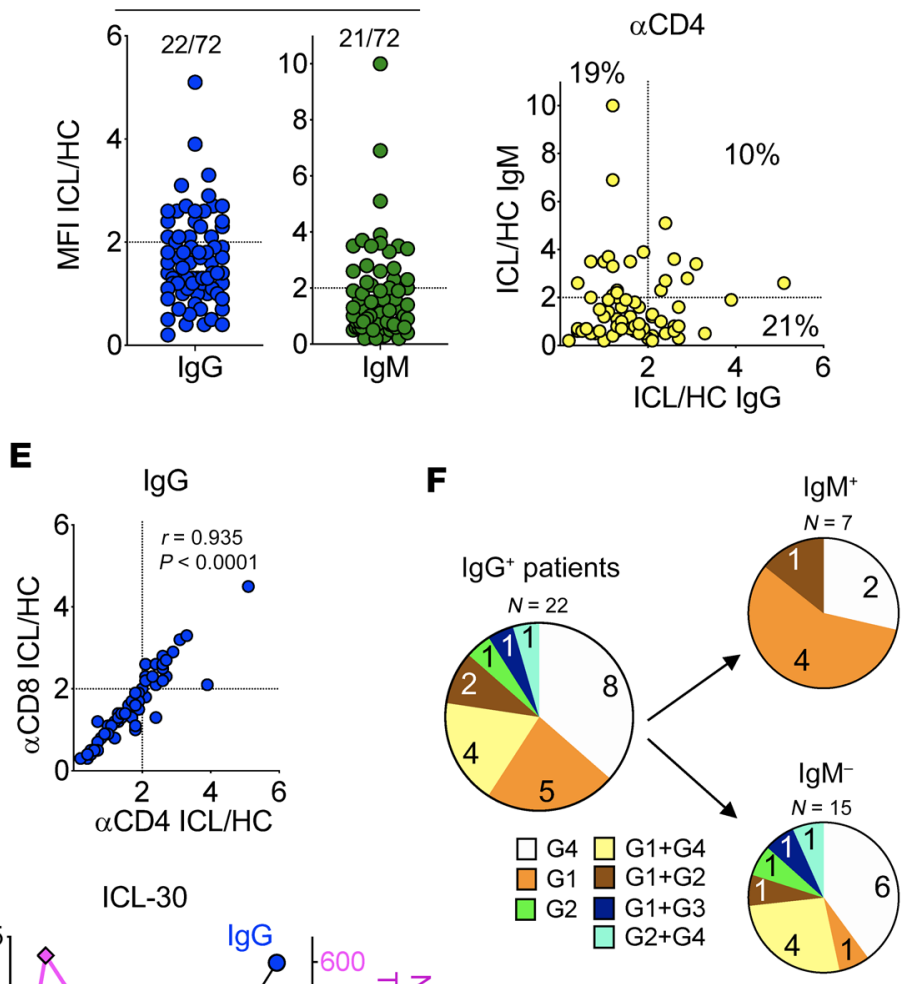

G ICL-18

ICL-50

ICL-30
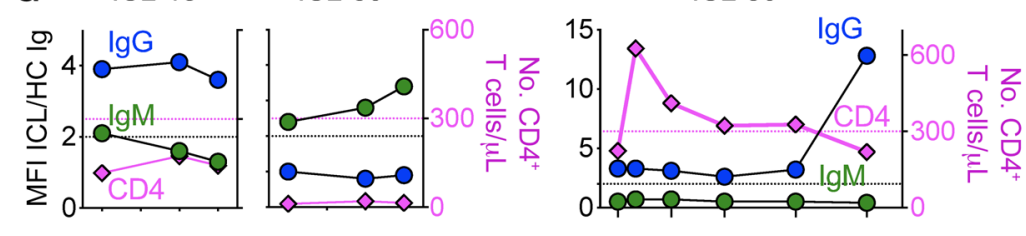

$\mathbf{F}$
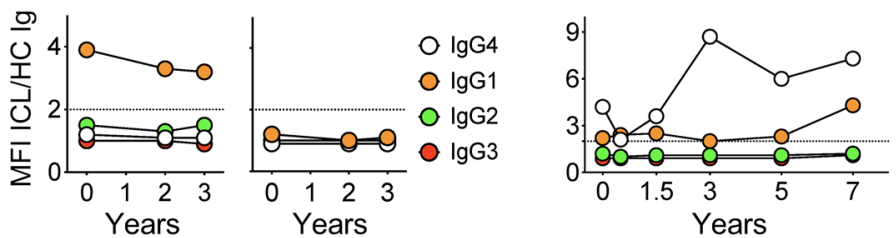

Figure 3. ICL patients have IgM and IgC Abs specific for membrane proteins expressed on CD3 $^{+} \mathrm{T}_{\text {cells }}$ and most of the IgG are IgC and IgG $\mathrm{G}_{4}$ isotypes. (A) Left and right histograms are representative examples of IgG and IgM deposition, respectively, caused by sera from ICL patients or HCs (in colors and black, respectively) on HC PBMCs. (B) Summary data representing the ratio of the IgG and IgM MFI of each patient over the MFI average of its experimental $\mathrm{HCs}$. A ratio $\geq 2$ was considered positive Ab deposition. Numbers are the fraction of positive patients for IgG or IgM, in blue and green, respectively. (C) Correlation of IgC vs. IgM autoantibodies specific for CD4+ $T$ cells found in the same patient. Numbers represent the percentages of patients with IgC and/or IgM autoantibodies. (D) IgC (blue) and IgM (green) Abs binding to CD8, NK, or B cells detected in the same way as in B. (E) Correlation of IgG autoantibody specific for $\mathrm{CD}^{+} \mathrm{T}$ cells vs. CD8 ${ }^{+} \mathrm{T}$ cells found in the same patient. $P$ and $r$ values were obtained by a 2-tailed Spearman's correlation. Data in B-E were pooled from 17 independent experiments done on 72 ICL patients and $30 \mathrm{HCs}$ as described in $\mathbf{A}$. (F) IgG subclass distribution of the anti-CD4 ${ }^{+} \mathrm{T}$ cell IgC autoantibody found in 22 ICL patients. The 22 patients were further divided based on whether they had anti-CD4+ cell IgM or not, with 7 and 15 patients, respectively. (G) Longitudinal measurements of CD4+ cell counts per $\mu \mathrm{L}$ of blood and anti-CD4+ $\mathrm{T}$ cell IgM, IgG, and IgG subclasses sampled over a 3-year period for ICL-18 (left) and ICL-50 (middle) and over a 7-year period for ICL-30 who was treated with rhIL-7 during the first 6 months. Time point 0 is the earliest serum sample we obtained for that particular patient.

patient's sera (Figure 3E). This correlation also existed with $\operatorname{IgG}$ anti-NK and anti-B cell Abs, but not as strongly (Supplemental Figure 3). These data suggest that the anti-CD4 ${ }^{+} \mathrm{T}$ cell Abs might recognize membrane proteins shared by cells of lymphocytic lineage, being the closest relationship between the $\mathrm{CD} 4^{+}$and $\mathrm{CD} 8^{+} \mathrm{T}$ cells (26) and therefore displaying the strongest correlation.

Using the same flow-based method, we next identified the IgG subclasses $\left(\operatorname{IgG}_{1}, \operatorname{IgG}_{2}, \operatorname{IgG}_{3}\right.$, or $\left.\operatorname{IgG}_{4}\right)$ of the anti-CD4 $4^{+} \mathrm{T}$ cell Abs. We found that of the 22 patients with anti-CD $4^{+}$cell IgG, the majority $(n=17)$ had $\operatorname{IgG}_{1}(n=5), \operatorname{IgG}_{4}(n=8)$, or both isotypes $(n=4)$ (Figure 3F). We next evaluated whether the presence of anti-CD4 ${ }^{+} \mathrm{T}$ cell IgM Abs would affect the IgG isotype distribution. Out of the $7 \mathrm{IgG} / \mathrm{IgM}$-double-positive ICL patients, the majority had $\operatorname{IgG}$ isotype $(n=4)$, while of the 15 ICL patients who were anti-CD $4^{+}$cell IgG positive but anti-CD $4^{+}$cell IgM negative, the predominant IgG subclass was $\operatorname{IgG}_{4}(n=6)$ either alone or combined with $\operatorname{IgG}_{1}(n=4)$. In summary, $\operatorname{IgG}_{1}$ and $\operatorname{IgG}_{4}$ seemed to be the predominant IgG subclasses in this cohort, with a slightly different distribution of the isotypes depending on the presence or absence of anti-CD $4^{+}$cell IgM autoantibodies. 
A

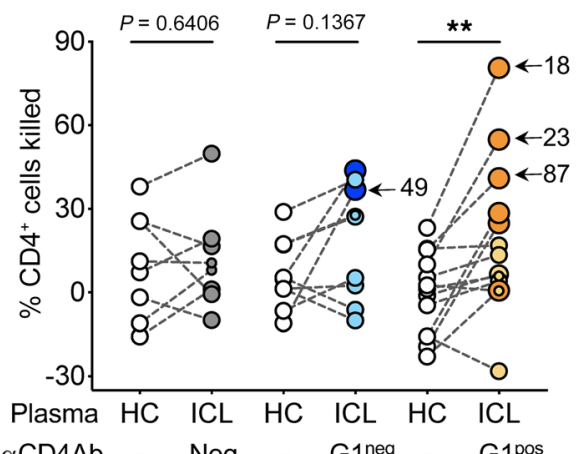

B
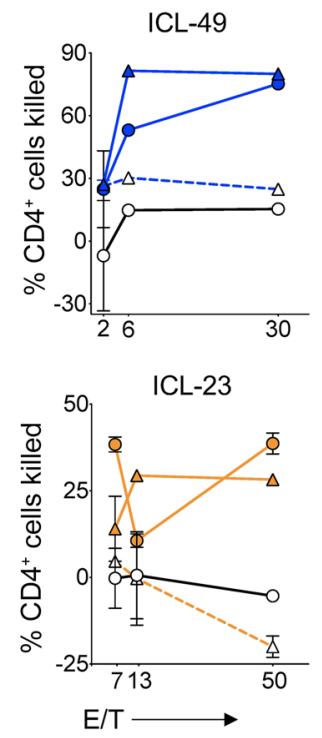

We next assessed the stability of these autoantibodies in 20 patients using longitudinal samples spanning between 3 and 7 years. We found that levels of $\operatorname{IgG}$ and IgM capable of binding to $\mathrm{CD}^{+} \mathrm{T}$ cells did not fluctuate drastically, as shown in 3 representative examples (Figure 3G). Similarly, the IgG subclasses also remained fairly stable over time. One of the 3 patients (ICL30) had participated in a previous study, in which ICL patients received IL-7 as an immunotherapeutic agent (27). This patient's $\mathrm{CD}^{+}$cell counts increased to above 300 cells $/ \mu \mathrm{L}$ immediately after IL-7 treatment (Figure 3G) despite continuously detectable serum levels of IgG autoantibodies against $\mathrm{CD} 4^{+} \mathrm{T}$ cells (showing at least a 2-fold shift in mean fluorescence intensity [MFI] compared with HC sera). Seven years after therapy, however, there was an unexplained sudden rise in autoantibodies against CD4 $4^{+}$ $\mathrm{T}$ cells, in conjunction with a drop in $\mathrm{CD} 4^{+}$counts, suggesting that anti-CD4 ${ }^{+} \mathrm{T}$ cell autoantibodies in some cases might potentially play a causative role in CD4 lymphopenia.

Abs against $C D 4^{+} T$ cells in ICL plasma induce ADCC of $C D 4^{+} T$ cells. We have shown that autoantibodies specific for $\mathrm{CD} 4^{+} \mathrm{T}$ cells are prevalent in ICL patients, but it remained unclear if they are functionally relevant. To test the function of these autoantibodies, we set up an NK ADCC assay, as described in the Methods. Different numbers of IL-2-activated NK cells were incubated with autologous CFSE-labeled HC target PBMCs that were previously incubated with either HC or ICL plasma. IgG Abs, and not IgM,
Figure 4. Abs found in ICL plasma induce Ab-dependent cell-mediated cytotoxicity (ADCC) of $\mathrm{HC} \mathrm{CD4}^{+} \mathrm{T}$ cells. Percentage of $\mathrm{HC} \mathrm{CD4} 4^{+} \mathrm{T}$ cells killed by ADCC as described in the Methods. (A) Paired median percentage of killing induced by ICL (closed circles) or by HC (open circles) plasma. Each pair of data represents 1 to 6 independent experiments in which the comparison between ICL and HC was done at a specific effector/target ratio $(E / T)$. Data pooled from 25 independent experiments with $E / T$ ranging between 40 and 60 . Bigger and darker blue and orange circles correspond to patients with positive ADCC killing, determined when the subtraction of percentage ICL killing minus percentage $\mathrm{HC}$ killing was greater than 20 . ICL patients were divided into 3 groups depending on anti-CD4 Ab presence and isotype: Neg. in gray, patients with no lgG $A b$; $G 1^{\text {neg }}$ in blue, patients with any IgG isotype other than IgG1; G1pos in orange, patients with IgG1 isotype. Numbers by the arrows identify the ICL patients with ADCC assays shown in B. ${ }^{* *} P<0.01$ by a 2-tailed, paired Wilcoxon's test. (B) Representative experiments showing ADCC of $C D 4^{+} T$ cells induced by the plasma from the 4 patients identified by arrows in $\mathbf{A}$, compared with $\mathrm{HC}$ plasma in open circles, at different $E / T$. We represent average percentage of killing from duplicate wells with their standard deviation. IgG was purified (purif.) from HC or ICL plasma as described in the Methods and it is shown in closed triangles. ADCC by IgG-depleted plasma is shown by dashed lines.

are capable of inducing ADCC, with human $\operatorname{IgG}_{3}$ and $\operatorname{IgG}_{1}$ isotypes exhibiting the highest capability (28). We tested plasma from the 22 ICL patients with IgG anti-CD4 $4^{+} \mathrm{T}$ cell Abs to assess potential induction of ADCC of $\mathrm{HC} \mathrm{CD} 4^{+} \mathrm{T}$ cells. Because the only patient with $\operatorname{IgG}_{3}$ had also $\operatorname{IgG}_{1}$ (Figure $3 \mathrm{~F}$ ), we divided the 22 patients into 2 groups, based on the presence or absence of $\mathrm{IgG}_{1}$ anti-CD4 ${ }^{+}$ cell $\mathrm{Ab}$, which would confer higher or lower, respectively, ADCC activity. In addition, we tested as controls 8 patients without IgG anti-CD4 ${ }^{+}$Abs, where we did not expect ADCC activity. Figure 4A shows that plasma from 8 ICL patients induced ADCC of HC $\mathrm{CD}^{+} \mathrm{T}$ cells. Six out of these 8 patients belonged to the $\mathrm{IgG}_{1}-$ positive group, and the other 2 to the IgG-negative group. No ADCC activity was observed in patients without IgG anti-CD4 ${ }^{+}$ cell Abs. Furthermore, IgG depletion from plasma of 4 patients led to loss of ADCC activity, which was recovered by the purified $\operatorname{IgG}$ fraction (Figure 4B). These data show that the IgG anti-CD4 ${ }^{+}$cell Abs found in ICL patients' plasma (particularly $\operatorname{Ig}_{1}$ ) can induce NK-dependent cytotoxicity of $\mathrm{CD} 4^{+} \mathrm{T}$ cells.

Abs found in ICL sera induce complement deposition and CDC of $C D 4^{+} \mathrm{T}$ cells. To further investigate the effector functions of the autoantibodies found in ICL sera, we assessed their ability to activate complement in vitro and induce $\mathrm{CDC}$ on $\mathrm{HC} \mathrm{CD} 4^{+} \mathrm{T}$ cells. $\mathrm{CDC}$ is induced mostly by $\operatorname{IgM}$ and $\operatorname{IgG}_{3}$ antibodies, although other IgG isotypes can also induce it less efficiently (29). To test for both complement deposition and CDC, we incubated HC PBMCs with either HC or ICL sera as previously done in Figure 3 , but this time, after washing the sera away, we further incubated the PBMCs with either normal human sera (to measure C3b deposition on $\mathrm{CD} 4^{+} \mathrm{T}$ cells by flow) or with rabbit sera (to test for CDC). Figure 5A shows that ICL-9 serum induced high levels of $\mathrm{C} 3 \mathrm{~b}$ deposition on $\mathrm{HC} \mathrm{CD} 4^{+} \mathrm{T}$ cells and that this deposition was dependent on the presence of total immunoglobulin (Ig). Using this method, we tested sera from all 72 patients, dividing them into 3 groups: patients without anti-CD $4^{+}$cell Abs, patients with IgG but not IgM anti-CD $4^{+}$cell $\mathrm{Abs}$, and patients with IgM anti$\mathrm{CD}^{+}$cell Abs. We found that 10 out of the $72(14 \%)$ patients' sera induced complement deposition on healthy $\mathrm{CD}_{4}{ }^{+} \mathrm{T}$ cells (Figure 
A

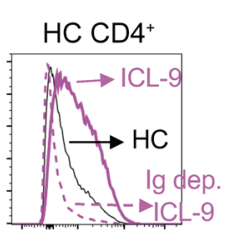

$\mathrm{C} 3 \mathrm{~b}$
B $\mathrm{C} 3 \mathrm{~b}$ on $\mathrm{HC} \mathrm{CD} 4^{+} \mathrm{T}$ cells

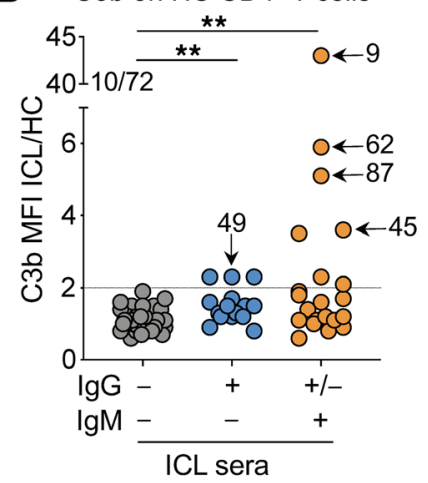

C

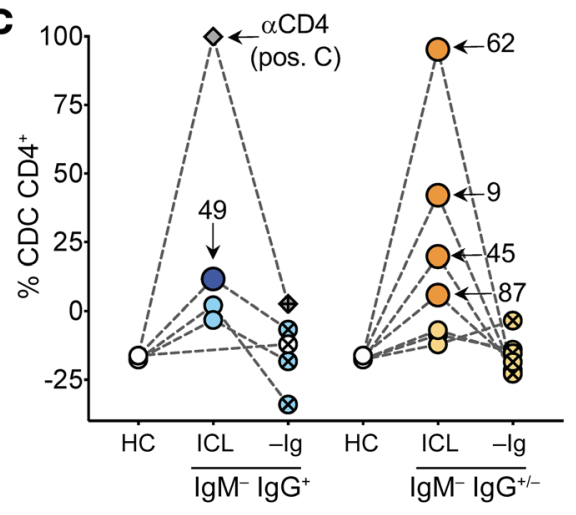

Figure 5. Abs against CD4 ${ }^{+} \mathrm{T}$ cells from ICL plasma or sera cause complement deposition on, and complement-dependent cytotoxicity (CDC) of, $\mathrm{CD4}^{+} \mathrm{T}$ cells. (A) Representative staining of $\mathrm{C3b}$ deposition induced by ICL-9 plasma (solid magenta), ICL-9 Ig-depleted plasma (dotted magenta), or pooled plasma from $10 \mathrm{HC}$ donors (solid black). (B) C3b deposition induced by ICL sera on $\mathrm{HC} \mathrm{CD4}^{+} \mathrm{T}$ cells, normalized to the deposition induced by $\mathrm{HC}$ sera. We considered a ratio $\geq 2$ (dotted line) positive for complement deposition. Sera samples were categorized into 3 groups based on their anti-CD4 Abs: gray circles, patients with no Abs; blue circles, patients with IgG (and not IgM) Abs; and orange circles, patients with IgM Abs. Number in upper left corner represents the number of patients capable of inducing complement deposition out of the total. Numbers with arrows identify the ICL patients whose sera induced CDC of HC CD4+ $T$ cells shown in C. Data pooled from 17 independent experiments. ${ }^{* *} P<0.01$ by 2 tailed Kruskal-Wallis test with Dunn's multiple-comparisons test. (C) CDC induced by ICL sera (blue and orange circles) paired by dashed lines with the CDC obtained by the HC sera (open circles) in the same experiment and with the CDC obtained after Ig depletion (crossed circles). Data were pooled from 3 independent experiments where each of the 10 patients that tested positive for complement deposition shown in B was tested 2 to 3 times. Medians for both ICL and HC are shown. Same color code as in B with bigger and darker circles corresponding to patients with positive CDC, determined when the subtraction of percentage ICL killing minus percentage HC killing was greater than 20. In gray diamonds, a mouse IgC2a anti-human CD4 Ab was used as positive control, with and without Ig depletion.

$5 \mathrm{~B})$ and that the majority of the positive patients (7 out of 10$)$ had IgM autoantibodies. We then tested sera from these 10 patients for their ability to induce CDC and found that 4 of the IgM-positive patients and 1 of the IgM-negative group induced CDC in an Ig-dependent manner, as Ig depletion resulted in the loss of CDC activity (Figure $5 \mathrm{C}$ ). These data demonstrate that anti-CD4 Abs found in ICL sera, particularly if they are of the IgM isotype, can cause complement deposition and $\mathrm{CDC}$ of $\mathrm{CD} 4^{+} \mathrm{T}$ cells.

Interestingly, similar to ICL patients, we observed IgG and IgM anti-CD $4^{+}$cell Abs in 2 of the 4 patients that, after enrollment and evaluation in our ICL protocol, were identified to have genetic mutations known to cause primary immunodeficiencies (PIDs) (Supplemental Figure 4A). And again, similar to ICL patients, the serum from the patient with activated phosphoinositide 3-kinase $\delta$ syndrome that had IgM Abs was able to induce complement deposition on $\mathrm{CD} 4^{+} \mathrm{T}$ cells (Supplemental Figure $4 \mathrm{~B}$ ). These data suggest that our findings of autoantibodies in ICL patients might also be relevant to other diseases with lymphopenia.

$C D 4^{+} T$ cells from ICL patients show evidence of in vivo classical complement activation. To seek evidence of potential in vivo complement activity targeting $\mathrm{CD} 4^{+} \mathrm{T}$ cells, we analyzed PBMCs from ICL patients directly ex vivo by flow cytometry, without any further incubation or stimulation. We stained these PBMCs with $3 \mathrm{com}$ plement protein fragments (C3b, C1q, and C4c) that under normal conditions should not be present in the membrane of $\mathrm{CD} 4^{+} \mathrm{T}$ cells. $\mathrm{C} 3 \mathrm{~b}$ is a fragment of $\mathrm{C} 3$ that is cleaved during the activation of any of the 3 complement pathways (classical, lectin, and alternative). $\mathrm{C} 1 \mathrm{q}$ is a fragment obtained after cleavage of $\mathrm{C} 1$ protein character- istic of the classical complement pathway and $\mathrm{C} 4 \mathrm{c}$ is a fragment of $\mathrm{C} 4$ protein cleaved during the activation of lectin or classical complement pathways (30,31). Staining for the 3 fragments allowed us to first, explore whether there is in vivo complement deposition on $\mathrm{CD} 4^{+} \mathrm{T}$ cells from ICL patients and second, which complement pathway is being triggered. We found that 10 out of 72 (14\%) ICL patients had complement deposition on their $\mathrm{CD} 4^{+} \mathrm{T}$ cells (Figure $6 \mathrm{~A}$ ), with all 10 staining for both $\mathrm{C} 3 \mathrm{~b}$ and C1q, identifying the classical pathway as the one being triggered in vivo. This conclusion was further supported by the finding of $\mathrm{C} 4 \mathrm{c}$ deposition with a similar intensity as C1q (Supplemental Figure 5A). In contrast, $\mathrm{HC} \mathrm{CD} 4^{+} \mathrm{T}$ cells and the rest of the ICL patients (see ICL-34 as an example) displayed negligible $\mathrm{C} 3 \mathrm{~b}$ or $\mathrm{C} 1 \mathrm{q}$ deposition (Figure 6A).

We next tested whether the complement deposition observed on the $\mathrm{CD} 4^{+} \mathrm{T}$ cells from the 10 ICL patients could be attributed to a lack or diminished expression of the complement inhibitory proteins CD55 and CD59. These proteins are ubiquitously expressed on cell membranes to protect them from complement activation directed against pathogens by inhibiting either the $\mathrm{C} 3$ convertase (CD55) or the formation of the membrane attack complex (MAC) (CD59) (32-34). We found a slight upregulation of the complement inhibitor CD59 on $\mathrm{CD} 4^{+}$ $\mathrm{T}$ cells from the 10 ICL patients with in vivo complement deposition compared with the rest of the patients or the HCs (Figure 6B), suggesting a cellular compensatory mechanism that protects the $\mathrm{CD} 4^{+} \mathrm{T}$ cells from $\mathrm{CDC}$. There was no difference in the expression level of complement inhibitor CD55 (Supplemental Figure 5B). Looking for additional evidence of in vivo complement activation, we next measured circulating immune complexes (CICs) binding $\mathrm{C} 1 \mathrm{q}$ or $\mathrm{C} 3 \mathrm{~d}$, complement proteins $\mathrm{C} 1 \mathrm{q}, \mathrm{C} 5 \mathrm{a}$, and $\mathrm{C} 9$, and $50 \%$ hemolytic complement $\left(\mathrm{CH}_{50}\right)$ equivalent enzyme immune assay (Eq EIA) in the sera or plasma of ICL patients (Supplemental Table 6). We found that the 10 patients with complement deposition on their $\mathrm{CD}^{+} \mathrm{T}$ cells had significantly lower classical complement activity $\mathrm{CH}_{50}$ Eq EIA remaining in their sera (Figure 6C). These data suggest that the presence of autoantibodies against $\mathrm{CD} 4^{+} \mathrm{T}$ cells triggers the classical complement pathway in vivo on $\mathrm{CD}^{+} \mathrm{T}$ cells in a proportion of ICL patients.

The presence of $A D C C$ or complement-inducing anti-CD4 Abs is associated with severe CD4 lymphopenia. We found a significant overlap between the 10 patients that displayed complement deposition on their $\mathrm{CD} 4^{+} \mathrm{T}$ cells ex vivo and the ones whose sera induced in vitro complement deposition on $\mathrm{HC} \mathrm{CD} 4^{+} \mathrm{T}$ cells, but 

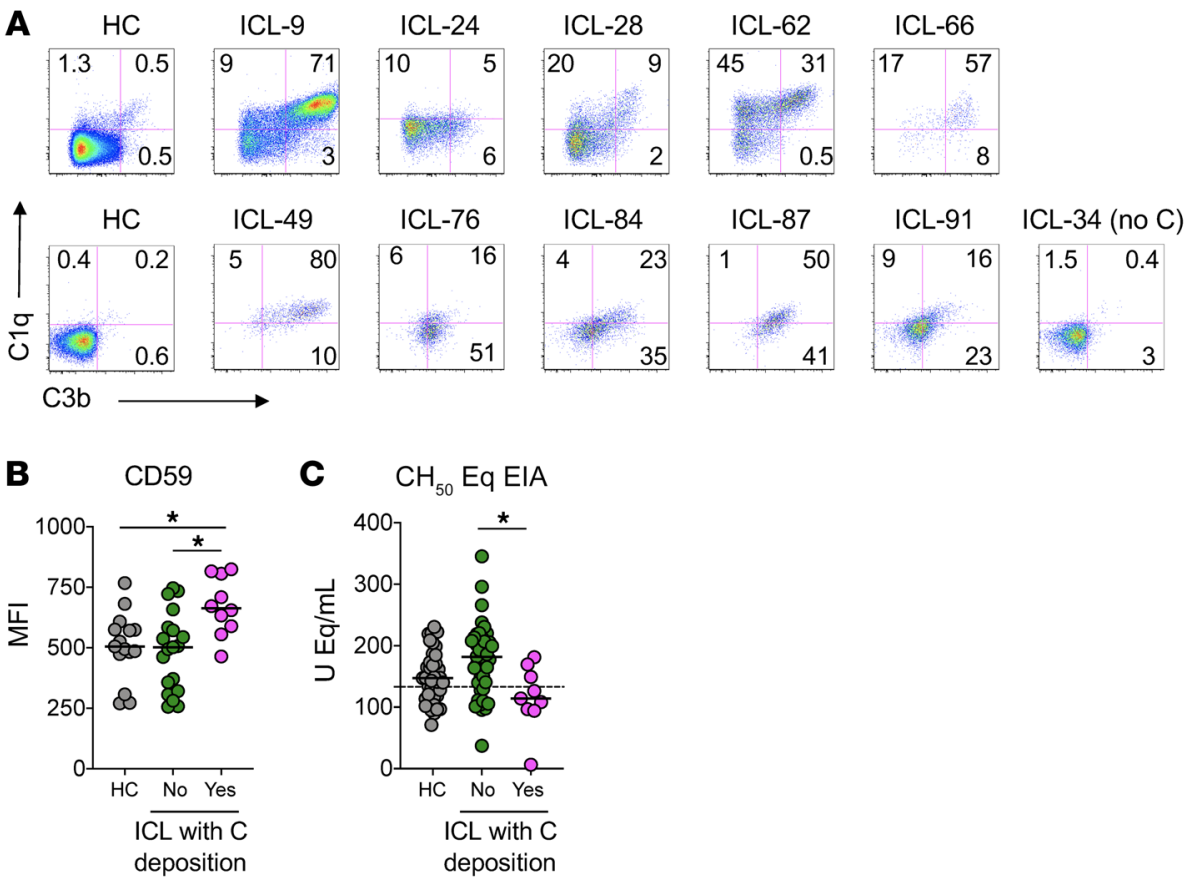

not with the group of patients whose plasma induced ADCC (Supplemental Figure 6A). To determine the relationship among all the different phenotypes, we summarized in a table the data obtained on anti-CD $4^{+}$cell Abs, their ADCC or complement function, as well as the degree of CD4 lymphopenia and autoimmunity status at an individual level (Supplemental Figure 6B). We found no association between the presence of Abs against $\mathrm{CD} 4^{+} \mathrm{T}$ cells (in green), or the presence of Abs with ADCC or complement activity (in orange), or degree of CD4 lymphopenia (in red), and the clinical autoimmune status of the patient. There seemed to be, however, a correlation between ADCC/complement-inducing Abs and a higher degree of lymphopenia that we further analyzed. In order to quantify this correlation, we divided the patients into 2 groups based on their blood $\mathrm{CD} 4^{+}$cell count: a moderate lymphopenia group, with $\mathrm{CD}^{+}$count equal to or above the cohort median of 75 cells $/ \mu \mathrm{L}$; and a severe lymphopenia group, with $\mathrm{CD} 4^{+}$count less than 75 cells $/ \mu \mathrm{L}$. We did not find difference in prevalence of anti$\mathrm{CD} 4 \mathrm{Abs}$ (IgG or IgM) between the 2 groups (Figure 7A), suggesting that the mere presence of anti-CD4 $4^{+}$cell Abs is not associated with the degree of lymphopenia. We then evaluated the association between the presence of ADCC or complement-inducing anti-CD4 ${ }^{+}$cell Abs and the degree of lymphopenia. We found a higher proportion of patients with functional autoantibodies in the more severely lymphopenic group (Figure 7B). Indeed, patients with these Abs were almost 6 times more likely to have profound lymphopenia compared with patients without them (odds ratio 5.71, CI 1.78-17.14, $P<0.01$ ). These data suggest a robust association between $\mathrm{ADCC} /$ complement-inducing anti- $\mathrm{CD} 4^{+} \mathrm{T}$ cell $\mathrm{Abs}$ and CD4 lymphopenia.

\section{Discussion}

In this study we show that ICL patients, independently of their clinical autoimmune diagnosis, have a broad spectrum of IgG and IgM autoantibodies directed against both intra- and extracellular targets. We also demonstrate how these autoantibodies can have functional consequences by triggering ADCC or complement activation or $\mathrm{CDC}$ on healthy $\mathrm{CD} 4^{+} \mathrm{T}$ cells. These observations, further supported by the presence of complement activation on patients' own T cells, provide evidence of the potential contribution of autoantibodies to lymphopenia.

Using 2 different types of antigen arrays, we found that all ICL patients tested had a wide quantitative and qualitative range of autoantibodies. The proteins recognized by autoantibodies in ICL patients showed a remarkable interindividual variability, perhaps explaining the high heterogeneity of autoimmune diseases affecting one-third of the ICL patients (2).

Previous studies suggested that the observed increase in apoptosis by $\mathrm{CD}^{+}{ }^{+} \mathrm{T}$ cells in ICL plays a role in the generation of anti-nuclear antibodies (ANAs) $(35,36)$. Yet, it was still unclear whether these autoantibodies are antilymphocytic and therefore could play a role in inhibiting $\mathrm{CD} 4^{+} \mathrm{T}$ cell recovery. In one case report, however, the authors reported an ICL patient with $\mathrm{CD} 4^{+} \mathrm{T}$ cells coated with autoantibodies (37). In our present work analyzing a large cohort of 72 ICL patients, we found that half of them harbor IgG or IgM anti-CD $4^{+} \mathrm{T}$ cell Abs. Functionally, the sera or plasma from half of the ICL patients with anti-CD4 ${ }^{+}$cell Abs induced either NK-mediated ADCC or complement deposition on $\mathrm{HC} \mathrm{CD} 4^{+} \mathrm{T}$ cells and most importantly, the presence of such Abs increased almost 6 times the probability of ICL patients to be more severely lymphopenic. Most of the anti-lymphocyte Abs that caused ADCC were $\operatorname{Ig} G_{1}$, while the anti-lymphocyte Abs that caused complement deposition were $\operatorname{Ig} G_{1}$ and IgM, consistent with the isotypes' anticipated functional potential (28). The majority of the IgG Abs were $\operatorname{IgG}_{1}$ (in general the most prevalent isotype), and $\operatorname{Ig}_{4}$, which is typically the least abundant; $\operatorname{IgG}_{4}$ can be indicative of chronic antigenic stimulation and it might play a role in inhibiting immediate hypersensitivity reactions (38). It has been previously shown that in SLE, isotype switching from clinical IgM to IgG Abs follows 
A
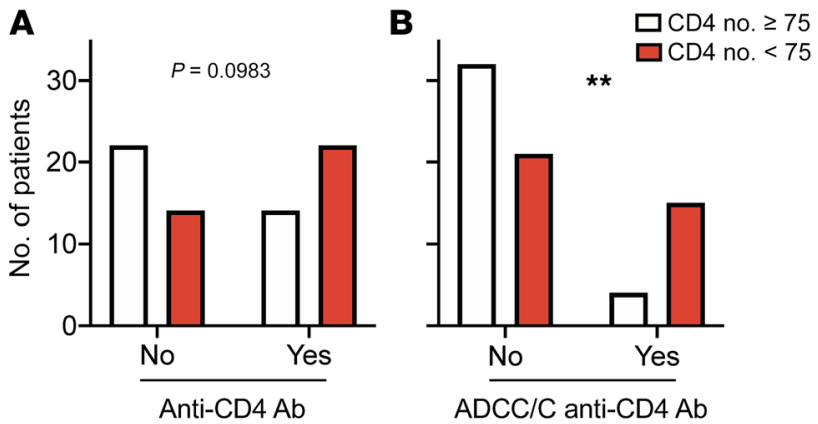

Figure 7. The presence of ADCC or complement-inducing anti-CD4 ${ }^{+}$cell Abs is associated with severe CD4 lymphopenia. We divided the cohort of $72 \mathrm{ICL}$ patients into 2 groups, according to their moderate (CD4+ numbers equal or above the median of $75 \mathrm{CD} 4^{+}$cells/ $\mu \mathrm{L}$ blood, in white) or severe (CD4 ${ }^{+}$numbers below 75 , in red) lymphopenia. (A) Number of patients with or without anti-CD4+ cell Abs (IgC or IgM) in each of the 2 groups. (B) Number of patients with or without anti-CD4+ cell Abs with ADCC or complement activity (ADCC/C) in each of the 2 groups. Complement activity includes both in vitro and in vivo complement activation. ${ }^{* *} P<0.01$ by 2-tailed Fisher's exact test with Baptista-like odds ratio of 5.71 (1.78-17.14).

disease progression (19). Isotype switching might have occurred in our cohort since we found a lack of correlation between IgG and IgM anti-CD4 $4^{+} \mathrm{T}$ cell Abs in the same patient. We did not observe, however, isotype switching in the patients we tested longitudinally over the course of a few years. One possibility is that more time is required to visualize the isotype switch. Another possibility is that continuous antigenic stimulation is maintaining the IgM levels. Because the duration of lymphopenia in ICL patients is generally unknown and probably varies among patients, it is also possible that many of the ICL patients who had been lymphopenic for a longer period of time are the ones with IgG autoantibodies, while the ICL patients who had been lymphopenic for a shorter period of time are the ones with the IgM isotype.

Because both the in vitro assays for ADCC and CDC use HC PBMCs as targets, it is possible that these assays have underestimated the cytotoxicity of the autoantibodies because a small proportion of the Abs might be specific for protein alleles not shared between the particular ICL patient and the HC PBMCs used for the assay. In addition, other than causing cytotoxicity, future studies will be needed to further elucidate the possible role of these Abs in binding receptor molecules on the $\mathrm{T}$ cell membrane and either inducing or blocking signaling cascades depending on whether they act as agonists or antagonists of such receptors, respectively.

Although autoimmunity had been described as part of the ICL clinical spectrum, the possibility that it may actually be playing a significant pathogenic role had not been previously investigated. Despite the great differences in clinical and immunological presentations characteristic of ICL patients, we found that the prevalence of autoantibodies was the unifying feature in our large cohort of patients. It remains unclear if autoimmunity, perhaps following a trigger event(s) in persons with genetic predisposition, might have an etiological role in ICL. On one hand, in autoimmune diseases such as SLE or rheumatoid arthritis the presence of autoantibodies can precede the clinical manifestations $(39,40)$. On the other hand, in both human and animal studies lymphopenia and lymphopenia-induced proliferation of the remaining T cells can lead to expansion of self-recognizing clones and break of tolerance with generation of autoantibodies $(9,11,41-43)$. Based on these previous reports and ours, our current working model is that an initial unknown trigger causes CD4 lymphopenia in ICL patients, which drives activation of the remaining $\mathrm{CD}^{+} \mathrm{T}$ cells by homeostatic expansion. The activated $\mathrm{CD} 4^{+} \mathrm{T}$ cells interact with autoreactive $\mathrm{B}$ cells, disrupting peripheral tolerance mechanisms and prompting the generation of autoantibodies. The initial autoantibody response might be further amplified, diversified, and self-sustained by mechanisms observed in autoreactive germinal centers (44), where the autoreactive B cells evolve with time toward pauciclonality. Both the Abs' specificity and effector functions, provided by their Fc portion, will determine their functional and clinical consequences ranging from totally innocuous to causing autoimmunity. If the initial trigger that caused the lymphopenia persists, as might be the case with genetic mutations, for instance in primary immunodeficiencies, the presence of anti-CD4 Abs would worsen the $\mathrm{CD} 4$ lymphopenia. If the initial trigger is transient, as might be the case with environmental triggers, the presence of autoantibodies might be sufficient to maintain the lymphopenia even after the resolution of the initial insult. $\mathrm{CD} 4^{+} \mathrm{T}$ cells share most of their transcriptome with $\mathrm{CD} 8^{+} \mathrm{T}$ cells (26), so it is not surprising that most of the anti-CD4 Abs can also target $\mathrm{CD} 8^{+} \mathrm{T}$ cells in accordance with our findings. We have previously suggested that $\mathrm{CD} 8$ lymphopenia is also a prominent feature of ICL and may even relate to disease prognosis (2). It is unclear why CD8 lymphopenia is not more commonly observed. $\mathrm{CD} 4^{+}$and $\mathrm{CD} 8^{+} \mathrm{T}$ cell numbers are regulated by independent homeostatic mechanisms. It has been shown that in adult humans $\mathrm{CD} 8^{+} \mathrm{T}$ cells have more regenerative potential than $\mathrm{CD} 4^{+} \mathrm{T}$ cells (45), making $\mathrm{CD} 8^{+} \mathrm{T}$ cells more resilient to lymphopenia. It is also possible, as suggested in animal models, that a threshold of $\mathrm{CD}^{+}$cells is needed to support homeostasis of $\mathrm{CD} 8^{+}$cells and when such threshold is surpassed CD8 lymphopenia ensues (46). Our observations on anti-lymphocyte Abs with lytic potential may go beyond ICL and be relevant to other diseases associated with lymphopenia, including PIDs (47). This is supported by our finding of autoantibodies and complement deposition induced by sera from 2 patients who initially enrolled in our ICL study to later be diagnosed with a specific PID.

We have recently identified a subgroup of ICL patients whose $\mathrm{T}$ cells, once outside their human environment, were able to reconstitute a lymphopenic host similarly to $\mathrm{T}$ cells from HCs (8). These findings suggest that in approximately half of the ICL patients the lymphopenia is driven by factors extrinsic to $\mathrm{CD}^{+} \mathrm{T}$ cells. In the other half of the ICL patients, $\mathrm{T}$ cells were not able to reconstitute the lymphopenic host, pointing to a $\mathrm{T}$ cell-intrinsic driver of the lymphopenia. Although we found autoantibodies and ADCC activity in sera from patients belonging to both groups, it is possible that the reconstituting group of ICL patients incorporates patients whose autoantibodies might be playing a more prominent role in their lymphopenia; this subgroup may be more likely to benefit from therapies focusing on inhibiting the Ab response.

In conclusion, our study shows that ICL patients have IgM and IgG autoantibodies of broad specificity, some of which have anti-lymphocyte reactivity that can cause cytotoxicity. These autoantibodies may be contributing to CD4 lymphopenia and may thus represent a novel therapeutic target. Potential therapeutic 
strategies could entail suppressing the production of autoantibodies as planned currently by our group at the NIH with belimumab (48), or even the consideration of a more direct approach to inhibit complement activation in a select group of patients (49). Attempting to treat an autoimmune disease in people with an underlying immune deficiency that puts them at risk for opportunistic infections poses unique challenges but at the same time may be a promising therapeutic approach.

\section{Methods}

ICL patients and HC study participants. Study participants provided PBMCs, sera, and plasma through enrollment in the clinical protocol "Etiology, Pathogenesis, and Natural History of Idiopathic CD 4 ${ }^{+}$Lymphocytopenia" (https://clinicaltrials.gov/ct2/show/NCT00867269) or through the NIH blood bank for HCs. Eligible ICL participants were adults with confirmed ICL $\left(\mathrm{CD} 4^{+} \mathrm{T}\right.$ cell count $<300 / \mu \mathrm{L}$ at screening and on at least one other occasion, at least 6 weeks apart, in the absence of any illness, treatment, or condition accounting for CD4 lymphopenia). HC PBMCs, sera, and plasma were collected through the NIH blood bank. Clinical autoantibodies used to classify ICL patients into groups 1, 2, and 3 were: ANA, at least 1 value above $3 \mathrm{EU}$; dsDNA, at least one value above $30 \mathrm{IU} / \mathrm{mL}$; anti-extractable nuclear antigen (anti-ENA), anti-SmRNP, anti-Smith (SM), SSA, SSB, Jo-1, and Scl-70 - at least 1 value above $25 \mathrm{EU}$ (strongly positive); anti-cardiolipin IgG (>18 glucagon-like peptide [GLP]); anti-centromere Ab (ACA) $\operatorname{IgM}$ (>22 GLP); anti- $\beta 2$ glycoprotein 1 IgG, IgG, IgM, IgA values greater than $15 \mathrm{IU} / \mathrm{mL}$; anti-thyroglobulin $\mathrm{Ab}$ values greater than $40 \mathrm{IU} /$ $\mathrm{mL}$; or thyroid peroxidase $\mathrm{Ab}$ greater than $35 \mathrm{IU} / \mathrm{mL}$. Those in group 3 fulfilled American College of Rheumatology or other society-defined criteria for the following diseases: autoimmune hemolytic anemia or idiopathic thrombocytopenic purpura (ITP), atopic dermatitis, SLE, pernicious anemia, psoriasis, psoriatic arthritis, discoid or other cutaneous lupus, autoimmune hypothyroidism (Hashimoto's thyroiditis), Graves disease, Crohn's diseases, ulcerative colitis, dermatitis herpetiformis/gluten-sensitive enteropathy, and vitiligo.

Screening for Abs against known autoantigens with an autoantigen array. Sera from 51 ICL patients and $25 \mathrm{HCs}$ pretreated with DNase I were diluted 1:50 and hybridized to an autoantigen array containing 128 antigens (https://microarray.swmed.edu/products/category/ protein-array) (19). After washes, Abs bound to the array were detected with Cy3-labeled anti-human IgG and Cy5-labeled anti-human IgM secondary Abs. A GenePix 4400A Microarray Scanner was used to scan the arrays, and GenePix 7.0 software to analyze fluorescence intensities (both Molecular Devices). PBS signal intensity was subtracted from the average signal intensity from duplicate spots to generate the average net fluorescence intensity (NFI). The signal to noise ratio (SNR) was calculated as (NFI - median background signal intensity)/SD of the background intensity. The Ab score was calculated as $\log _{2}(\mathrm{SNR} \times \mathrm{NFI}+1)$. The Ab scores were further used for batch correction. The batch effects were removed using a nonparametric empirical Bayes approach (50). $Z$ scores were calculated as the number of SDs of the $\mathrm{Ab}$ score from the mean of HCs.

$A b$ profiling by ProtoArray. Sera from 34 ICL patients and 15 age-matched HCs were diluted 1:500 in PBS with Tween. The sera were then incubated on the Human Protein Microarray v5.1 (Thermo Fisher Scientific) displaying more than 9,000 human proteins. Alexa Fluor 647-conjugated anti-human IgG was used as secondary Ab.
The array slides were scanned with a GenePix 4000B fluorescence scanner (Molecular Devices). ProtoArray data were preprocessed for background correction, batch filtering, and data normalization using the PAA package $(51,52)$. Spot duplicates were condensed by taking the smaller value and only proteins with relative fluorescence units (RFUs) greater than 500 in at least one sample were selected for further analysis. $Z$ scores were calculated as the number of SDs of signal from the mean of the HC group. Proteins targeted by autoantibodies were analyzed through the use of Ingenuity Pathway Analysis (QIAGEN Inc., https://www.qiagenbioinformatics.com/products/ ingenuity-pathway-analysis) to identify possible associated upstream transcriptional regulators and molecular and cellular functions that may be affected.

Flow cytometry. Cells were blocked with anti-human CD16/32 Ab (BD Biosciences) for 10 minutes before adding fluorochrome-conjugated Abs (Supplemental Table 6). We used 7-AAD (BD Biosciences) or LIVE/DEAD blue, aqua, near-IR fixable Dead Cell Stain kits (Invitrogen) to exclude dead cells. Cells were then incubated for 20 minutes at room temperature and washed once with $1 \%$ BSA in PBS before acquisition using a Fortessa or LSRII (both from BD Biosciences). Analysis was done with FlowJo (Tree Star) software (version 9.9.6 and above).

Detection of Abs against $\mathrm{CD} 4^{+}$and $\mathrm{CD} 8^{+}$T cell membrane molecules by flow cytometry. After blocking with anti-human CD16/32 antibody (BD Biosciences), 2 million HC PBMCs were incubated in $100 \mu \mathrm{L}$ of PBS or $100 \mu \mathrm{L}$ of plasma from either HC or ICL donors for 30 minutes at room temperature. Cells were washed once with PBS and then stained with fluorescently labeled anti-human $\operatorname{IgG}$, IgM, IgG $, \operatorname{IgG}_{2}, \operatorname{IgG}_{3}$, or $\operatorname{IgG}_{4}$ Abs (Supplemental Table 7) to detect the presence of autoantibodies targeting membrane molecules on $\mathrm{HC} \mathrm{CD}^{+} \mathrm{T}$ cells. For each Ig channel we calculated the MFI and identified the presence of anti-CD3 ${ }^{+} \mathrm{T}$ cell Abs when the ICL MFI/HC MFI ratio was 2 or greater.

NK-mediated ADCC. Using the EasySep Human NK Cell Isolation Kit (STEMCELL Technologies), NK cells were negatively selected from HC PBMCs and incubated with $1000 \mathrm{IU} / \mathrm{mL}$ of rhIL-2 (PeproTech) at $37^{\circ} \mathrm{C}$ overnight. A portion of the same HC PBMCs not used for NK cell isolation was incubated at $37^{\circ} \mathrm{C}$ overnight and used the following day as target cells. The target cells were labeled with $0.6 \mu \mathrm{M}$ CFSE and incubated with $100 \mu \mathrm{L}$ of plasma from either HCs or ICL patients for 30 minutes at room temperature. After washing with PBS, the target cells were plated in duplicate at 10,000 cells/well in a U-bottom 96-well plate. The autologous NK cells were then added at the described effector/target (E/T) ratios, except for 2 wells for each plasma donor where no NK cells were added as controls. After 4 hours the cells were harvested and stained for flow cytometry. We added counting beads (Thermo Fisher Scientific) to the FACS tubes immediately before analyzing them by flow cytometry. By adding the same known number of beads to all FACS tubes, we were able to quantify the live cells remaining in the wells in the presence or absence of NK effectors. We used these numbers to calculate the percentage of killing by applying the following formula: 100 - (number of target cells at a particular $\mathrm{E} / \mathrm{T}$ ratio/number of target cells in the absence of NK effectors) $\times 100$. Anti-CD20 antibody (Rituximab) was used for ADCC assays as positive control and only experiments where rituximab induced ADCC on B cells were used for analyses.

Complement deposition assay. PBMCs from HCs were incubated with $\mathrm{HC}$ or ICL sera as described above for the detection of Abs against $\mathrm{CD}^{+}$and $\mathrm{CD}^{+} \mathrm{T}$ cells by flow cytometry. During the 30-minute incu- 
bation, GVB buffer (CompTech Complement Technology Inc) was heated at $37^{\circ} \mathrm{C}$ and frozen normal human serum (NHS) (Cedarlane) was thawed on ice. NHS was diluted 1:30 in GVB buffer and $400 \mu \mathrm{L}$ of this dilution was added to the HC PBMC tubes after their incubation with $\mathrm{HC}$ or ICL serum. After a second incubation at $37^{\circ} \mathrm{C}$ for 1 hour with sporadic inversion of the tubes, cells were washed with PBS and stained with anti-C3b Ab (Supplemental Table 6) to detect complement deposition on $\mathrm{CD} 4^{+} \mathrm{T}$ cells by flow cytometry.

CDC. HC PBMCs were incubated with HC or ICL sera as described above for the detection of Abs by flow cytometry. As positive control, an aliquot of PBMCs was incubated with mouse IgG2a anti-human CD4 $\mathrm{Ab}$ (clone M-T477, BD Biosciences). During the 30-minute incubation of the PBMCs with HC or ICL serum, rabbit complement (Cedarlane) was reconstituted following manufacturer's instructions and diluted 1:4 in complete media with 10\% FBS. After the incubation with sera and washes, the PBMCs were resuspended in the rabbit complement medium and incubated at $37^{\circ} \mathrm{C}$ for 2 hours. After 2 washes with $1 \%$ BSA in PBS the samples were stained, fixed in $1 \%$ paraformaldehyde, and analyzed by flow cytometry using counting beads (Thermo Fisher Scientific) to obtain absolute cell numbers as described for the ADCC method. The percentage of CDC was calculated using the following formula: 100 - (number of CD4 $4^{+} \mathrm{T}$ cells incubated with serum/number of $\mathrm{CD} 4^{+} \mathrm{T}$ cells incubated with PBS) $\times 100$.

Immunoglobulin depletion and purification from human sera and plasma. Protein G HP SpinTrap (GE Healthcare) was used to deplete human sera of IgG following the manufacturer's instructions. Briefly, after the column storage buffer was removed by centrifugation for 30 seconds at $100 \mathrm{~g}$, the column was washed with $600 \mu \mathrm{L}$ of binding buffer (20 mM sodium phosphate, $\mathrm{pH}$ 7.0) and centrifuged for $30 \mathrm{sec}-$ onds at $100 \mathrm{~g}$. After diluting the HC or ICL patient sera 1:10 in binding buffer, $600 \mu \mathrm{L}$ was added to the spin trap and spun at $100 \mathrm{~g}$ for 30 seconds. The run-through was collected as IgG-depleted sera. To purify IgGs from human plasma, a Dynabeads Protein G Immunoprecipitation Kit (Thermo Fisher Scientific) was used as per the manufacturer's instructions. Briefly, plasma from HC or ICL patients was diluted 1:10 in the provided binding buffer. Protein $G$ beads were washed by placing the beads on the magnet and removing the storage buffer. The beads were resuspended in $50 \mu \mathrm{L}$ of binding buffer and added to $600 \mu \mathrm{L}$ of the diluted plasma. After a 10-minute incubation at room temperature with constant rotation, the samples were placed on the magnet and the supernatant was collected as IgG-depleted plasma. To isolate the IgG, $20 \mu \mathrm{L}$ of elution buffer was added to the beads and incubated for 3 minutes at room temperature. The samples were then placed on the magnet and the supernatant was collected as the purified IgG fraction.

To deplete total immunoglobulins from patient sera, a Pierce Thiophilic Adsorption Kit (Thermo Fisher Scientific) was used. After 3 washes with binding buffer, patient sera, diluted in binding buffer 1:3000, was loaded on the thiophilic adsorbent columns. The samples were allowed to completely enter the resin bed, before the column was washed with at least $12 \mathrm{~mL}$ of binding buffer. The flow-through was collected as the IgG- and IgM-depleted sera. Amicon Ultra-4 centrifugal filter units (MilliporeSigma) were used for buffer exchange, spinning at $3000 \mathrm{rpm}$ for 60 minutes for 8 exchanges.

Measurements of complement proteins and activity in serum and plasma from HC and ICL donors. CIC C1q (Buhlmann Diagnostics Corp.), CIC C3d, C1q, C5a, (Abcam), C9 (Cusabio), and $\mathrm{CH}_{50} \mathrm{Eq}$
EIA (Quidel Corporation) were measured with enzyme-linked immunosorbent assays in duplicate and after the first thaw of cryopreserved acid citrate dextrose plasma for all except for $\mathrm{CH}_{50} \mathrm{Eq}$ EIA, which was measured on cryopreserved sera and according to the manufacturers' instructions.

Statistics. Two-tailed nonparametric tests were used to compare ranks or differences between groups. GraphPad Prism (v. 8.1) was used for statistical tests. A P value less than 0.05 was considered significant. For autoantibody detection, Bonferroni's correction was used to calculate statistical significance. Python (version 3.5) and packages Pandas (0.22), Seaborn (0.90), and SciPy (1.3) were used for analysis of the protoarray data. Cluster maps were created based on Euclidean distances. R (3.5) was used for the Principal Component Analysis with the Vegan (2.5) package. Experiment-specific statistical methods are described in the figure legends.

Study approval. This study was approved by the Institutional Review Board of the NIAID, and informed consent was obtained from all participants before any study procedures in accordance with the Declaration of Helsinki.

\section{Author contributions}

Patient recruitment and care was provided by VS, AL, EL, AFF, PRW, MA, GR, and IS. Experimental design was provided by APD, RS, and IS. Generation and analysis of experimental data were provided by APD, CSW, XL, HM, JS, YL, JSB, CC, CZ, and QZL, with supervision by APD, RS, JST, and IS. APD, CSW, and IS wrote the manuscript.

\section{Acknowledgments}

The authors would like to thank the study participants and the staff in outpatient clinic 8 at the NIH Clinical Center. We would also like to thank Adam W. Rupert from Leidos Biomedical Research at NCI in Frederick for running the serum complement assays and UT Southwest Microarray Core Facility for the Autoantigen array analysis. This work was supported by the Divisions of Intramural Research of the NIAID and of the National Institute of Arthritis and Musculoskeletal and Skin Diseases of the NIH.

Address correspondence to: Ainhoa Perez-Diez, 10 Center Drive, Building 10, Room 11B17A, Bethesda, Maryland 20814, USA. Phone: 301.761.6698; Email: ainhoa@nih.gov. Or to: Irini Sereti, 10 Center Drive, Building 10, Room 11B15A, Bethesda, Maryland 20814, USA. Phone: 301.496.5533; Email: isereti@niaid.nih.gov.

VS's present address is: Division of Antiviral Products, Center for Drug Evaluation, Food and Drug Administration, Silver Spring, Maryland, USA.

JSB's present address is: Department of Molecular Genetics and Microbiology, School of Medicine, Duke University, Durham, North Carolina, USA.

GR's present address is: Division of AIDS, National Institute of Allergy and Infectious Diseases, NIH, Rockville, Maryland, USA.

RS's present address is: Novartis Institutes of Biomedical Research, Basel, Switzerland. 
1. Smith DK, Neal JJ, Holmberg SD. Unexplained opportunistic infections and CD4 ${ }^{+}$T-lymphocytopenia without HIV infection. An investigation of cases in the United States. The Centers for Disease Control Idiopathic $\mathrm{CD} 4^{+}$T-lymphocytopenia Task Force. N Engl JMed.1993;328(6):373-379.

2. Zonios DI, et al. Idiopathic $\mathrm{CD} 4^{+}$lymphocytopenia: natural history and prognostic factors. Blood. 2008;112(2):287-294.

3. Régent A, et al. Idiopathic CD4 lymphocytopenia: clinical and immunologic characteristics and follow-up of 40 patients. Medicine (Baltimore). 2014;93(2):61-72.

4. Yarmohammadi H, Cunningham-Rundles C. Idiopathic CD4 lymphocytopenia: Pathogenesis, etiologies, clinical presentations and treatment strategies. Ann Allergy Asthma Immunol. 2017;119(4):374-378

5. Scott-Algara D, et al. Idiopathic CD4 ${ }^{+} \mathrm{T}$-cell lymphocytopenia is associated with impaired membrane expression of the chemokine receptor CXCR4. Blood. 2010;115(18):3708-3717.

6. Hubert P, et al. Defective p56Lck activity in T cells from an adult patient with idiopathic $\mathrm{CD} 4^{+} \mathrm{lym}-$ phocytopenia. Int Immunol. 2000;12(4):449-457.

7. Isgrò $\mathrm{A}$, et al. Bone marrow clonogenic capability, cytokine production, and thymic output in patients with common variable immunodeficiency. JImmunol. 2005;174(8):5074-5081.

8. Perez-Diez A, Liu X, Sheikh V, Roby G, Stroncek DF, Sereti I. Humanized mouse models reveal an immunologic classification of idiopathic CD4 lymphocytopenia subtypes. JCI Insight. 2019;4(14):127802.

9. King C, Ilic A, Koelsch K, Sarvetnick N. Homeostatic expansion of $\mathrm{T}$ cells during immune insufficiency generates autoimmunity. Cell. 2004;117(2):265-277.

10. Khoruts A, Fraser JM. A causal link between lymphopenia and autoimmunity. Immunol Lett. 2005;98(1):23-31.

11. Krupica T, Fry TJ, Mackall CL. Autoimmunity during lymphopenia: a two-hit model. Clin Immunol. 2006;120(2):121-128.

12. Rivero SJ, Díaz-Jouanen E, Alarcón-Segovia D. Lymphopenia in systemic lupus erythematosus. Clinical, diagnostic, and prognostic significance. Arthritis Rheum. 1978;21(3):295-305.

13. Mirzayan MJ, Schmidt RE, Witte T. Prognostic parameters for flare in systemic lupus erythematosus. Rheumatology (Oxford). 2000;39(12):1316-1319.

14. Mandl T, Bredberg A, Jacobsson LT, Manthorpe R, Henriksson G. CD4 ${ }^{+}$T-lymphocytopenia--a frequent finding in anti-SSA antibody seropositive patients with primary Sjögren's syndrome. JRheumatol. 2004;31(4):726-728.

15. Lisco A, et al. Identification of rare HIV-1infected patients with extreme $\mathrm{CD} 4^{+} \mathrm{T}$ cell decline despite ART-mediated viral suppression. JCI Insight. 2019;4(8):127113.

16. Lisco A, et al. Paradoxical CD4 lymphopenia in autoimmune lymphoproliferative syndrome (ALPS). Front Immunol. 2019;10:1193.

17. Fischer A, Provot J, Jais JP, Alcais A, Mahlaoui $\mathrm{N}$, members of the CEREDIH French PID study group. Autoimmune and inflammatory manifestations occur frequently in patients with primary immunodeficiencies. J Allergy Clin Immunol. 2017;140(5):1388-1393.e8.

18. Kovacs SB, et al. T-cell depletion in the colonic mucosa of patients with idiopathic $\mathrm{CD} 4^{+}$lymphopenia. J Infect Dis. 2015;212(10):1579-1587.

19. Zhu H, Luo H, Yan M, Zuo X, Li QZ. Autoantigen microarray for high-throughput autoantibody profiling in systemic lupus erythematosus. Genomics Proteomics Bioinformatics. 2015;13(4):210-218.

20. Wiik A. Autoantibodies in vasculitis. Arthritis Res Ther. 2003;5(3):147-152.

21. van der Woude FJ, et al. Autoantibodies against neutrophils and monocytes: tool for diagnosis and marker of disease activity in Wegener's granulomatosis. Lancet. 1985;1(8426):425-429.

22. Sumida T, Tsuboi H, Iizuka M, Asashima H, Matsumoto I. Anti-M3 muscarinic acetylcholine receptor antibodies in patients with Sjögren's syndrome. Mod Rheumatol. 2013;23(5):841-845.

23. Moreland LW, Gay RE, Gay S. Collagen autoantibodies in patients with vasculitis and systemic lupus erythematosus. Clin Immunol Immunopathol. 1991;60(3):412-418.

24. Jaekel HP, et al. Reactivities to the Sm autoantigenic complex and the synthetic SmD1-aa83-119 peptide in systemic lupus erythematosus and other autoimmune diseases. JAutoimmun . 2001;17(4):347-354.

25. Meyer S, et al. AIRE-deficient patients harbor unique high-affinity disease-ameliorating autoantibodies. Cell. 2016;166(3):582-595.

26. Hidalgo LG, Einecke G, Allanach K, Halloran PF. The transcriptome of human cytotoxic $T$ cells: similarities and disparities among allostimulated CD4(+) CTL, CD8(+) CTL and NK cells. Am J Transplant. 2008;8(3):627-636.

27. Sheikh V, et al. Administration of interleukin-7 increases $\mathrm{CD} 4 \mathrm{~T}$ cells in idiopathic CD4 lymphocytopenia. Blood. 2016;127(8):977-988.

28. Vidarsson G, Dekkers G, Rispens T. IgG subclasses and allotypes: from structure to effector functions. Front Immunol. 2014;5:520.

29. Nesargikar PN, Spiller B, Chavez R. The complement system: history, pathways, cascade and inhibitors. Eur J Microbiol Immunol (Bp). 2012;2(2):103-111.

30. Nagasawa S, Ichihara C, Stroud RM. Cleavage of $\mathrm{C} 4 \mathrm{~b}$ by C3b inactivator: production of a nicked form of $\mathrm{C} 4 \mathrm{~b}, \mathrm{C} 4 \mathrm{~b}$ ', as an intermediate cleavage product of $\mathrm{C} 4 \mathrm{~b}$ by $\mathrm{C} 3 \mathrm{~b}$ inactivator. JImmunol. 1980;125(2):578-582.

31. Pangburn MK, Müller-Eberhard HJ. The alternative pathway of complement. Springer Semin Immunopathol. 1984;7(2-3):163-192.

32. Medof ME, Kinoshita T, Nussenzweig V. Inhibition of complement activation on the surface of cells after incorporation of decay-accelerating factor (DAF) into their membranes. JExp Med. 1984;160(5):1558-1578.

33. Rollins SA, Sims PJ. The complement-inhibitory activity of CD59 resides in its capacity to block incorporation of C9 into membrane C5b-9. JImmunol. 1990;144(9):3478-3483.

34. Ninomiya H, Sims PJ. The human complement regulatory protein $\mathrm{CD} 59$ binds to the alpha-chain of $\mathrm{C} 8$ and to the "b"domain of C9. J Biol Chem. 1992;267(19):13675-13680.
35. Laurence J, Mitra D, Steiner M, Lynch DH, Siegal FP, Staiano-Coico L. Apoptotic depletion of $\mathrm{CD}^{+}$ $\mathrm{T}$ cells in idiopathic $\mathrm{CD} 4^{+} \mathrm{T}$ lymphocytopenia. JClin Invest. 1996;97(3):672-680.

36. Bordin G, et al. Idiopathic CD $4^{+}$lymphocytopenia and systemic vasculitis. J Intern Med. 1996;240(1):37-41.

37. Salit RB, Hankey KG, Yi R, Rapoport AP, Mann DL. Detection of CD4(+) T-cell antibodies in a patient with idiopathic $\mathrm{CD} 4 \mathrm{~T}$ lymphocytopenia and cryptococcal meningitis. Br J Haematol. 2007;139(1):133-137.

38. Aalberse RC, Stapel SO, Schuurman J, Rispens T. Immunoglobulin G4: an odd antibody. Clin Exp Allergy. 2009;39(4):469-477.

39. Arbuckle MR, et al. Development of autoantibodies before the clinical onset of systemic lupus erythematosus. $\mathrm{N}$ Engl J Med. 2003;349(16):1526-1533.

40. van der Woude D, et al. Epitope spreading of the anti-citrullinated protein antibody response occurs before disease onset and is associated with the disease course of early arthritis. Ann Rheum Dis. 2010;69(8):1554-1561.

41. Iida S, Suzuki T, Tanabe K, Valujskikh A, Fairchild RL, Abe R. Transient lymphopenia breaks costimulatory blockade-based peripheral tolerance and initiates cardiac allograft rejection. $A m$ J Transplant. 2013;13(9):2268-2279.

42. Jones JL, et al. Human autoimmunity after lymphocyte depletion is caused by homeostatic T-cell proliferation. Proc Natl Acad Sci U S A. 2013;110(50):20200-20205.

43. Ellestad KK, Anderson CC. Two strikes and you're out? The pathogenic interplay of coinhibitor deficiency and lymphopenia-induced proliferation. J Immunol. 2017;198(7):2534-2541.

44. Degn SE, et al. Clonal evolution of autoreactive germinal centers. Cell. 2017;170(5):913-926.e19.

45. Mackall CL, et al. Distinctions between $\mathrm{CD}^{+}$ and $\mathrm{CD}_{4}{ }^{+} \mathrm{T}$-cell regenerative pathways result in prolonged T-cell subset imbalance after intensive chemotherapy. Blood. 1997;89(10):3700-3707.

46. Ayasoufi K, Fan R, Fairchild RL, Valujskikh A. $\mathrm{CD} 4 \mathrm{~T}$ cell help via $\mathrm{B}$ cells is required for lymphopenia-induced CD8 T cell proliferation. J Immunol. 2016;196(7):3180-3190.

47. Maggadottir SM, Sullivan KE. The intersection of immune deficiency and autoimmunity. Curr Opin Rheumatol. 2014;26(5):570-578.

48. Safety of belimumab in people with idiopathic CD4 lymphopenia and autoantibodies (Phoebe). https://clinicaltrials.gov. NCT04097561. Accessed July 17, 2020.

49. Ricklin D, Lambris JD. Complement in immune and inflammatory disorders: pathophysiological mechanisms. J Immunol. 2013;190(8):3831-3838.

50. Johnson WE, Li C, Rabinovic A. Adjusting batch effects in microarray expression data using empirical Bayes methods. Biostatistics. 2007;8(1):118-127.

51. Turewicz M, Ahrens M, May C, Marcus K, Eisenacher M. PAA: an R/bioconductor package for biomarker discovery with protein microarrays. Bioinformatics. 2016;32(10):1577-1579.

52. Turewicz M. Protein array analyzer. https:// bioconductor.org/packages/release/bioc/ html/PAA.html. 